\title{
SPECIALIZATION IN SERVICES: A CANADIAN EXAMPLE
}

\author{
Jim Simmons \\ Centre for the Study of Commercial Activity, 1617 Ross St., \\ Victoria BC V8S IJ7, Canada \\ e-mail: jimsimmons@shaw.ca
}

\begin{abstract}
In modern urban systems the economic growth of cities is largely driven by services. In many regions employment growth in primary and secondary activities is close to zero, or even negative. Growth depends on the ability to attract jobs in the services. This study explores the pattern of specialization in various service activities for 159 Canadian urban areas in 1996, as the basis for a series of maps for the Atlas of Canada. The hierarchical specialization is evaluated for each service sector by computing a regression model of service employment as a function of urban population and income per capita. The rapidly growing business and financial services are the most strongly oriented to larger cities. The horizontal specialization is measured as residuals from the regressions. Strong regional differences contrast the central place roles of agricultural communities with the more localized markets of resource and manufacturing centres. Public sector decisions about the location of major health and education facilities complement the choices of the private sector.
\end{abstract}

Key words: economic specialization, urban system, services.

\section{INTRODUCTION}

When I first began to teach urban geography a couple of generations ago, the approach to urban growth began with the concept of economic base. Jobs in mines or factories (the 'basic' activities) attracted a population that purchased goods and services, and thus created 'non-basic' employment. Understanding urban growth was reduced to the study of location theory for producer activities. Forty years later, the sequence is reversed. The employment in primary sectors is declining; manufacturing jobs are disappearing as fast as they are being created; and in Canada, at least, almost all the growth in employment occurs within the services. Urban growth depends on the growth of markets, and on the location requirements of the services that the markets require.

The markets for services that used to derive from nearby agriculture and manufacturing may now originate from other sources and locations. The Province of Alberta in Can- 
ada, for example, sits on extensive oil and gas deposits that have generated widespread prosperity - expressed in the consumption of both private and public services. Two of Canada's largest cities, Toronto and Vancouver, have attracted 100,000s of immigrants that have increased the size of the local markets and stimulated growth in nearby cities, as well. Smaller resort and retirement centres serve markets that are widely dispersed. Huge hypermarkets select the small towns that are most accessible to a region. Most of you are familiar with these contemporary urban growth processes. The question for this paper: where do these services locate? What kinds of cities attract the various categories of service activities?

\section{THE LOCATION OF SERVICE ACTIVITIES}

Table 1 gives a sense of the size and growth trends in the service sectors in Canada through 1996. Private sector services provided 5.8 million jobs in 1996, after adding 1.2 million jobs with a growth rate of 26 per cent over the previous decade. Public sector services contributed 3.1 million jobs, with a growth of 500,000 jobs (18.0 per cent). The remaining sectors of the economy - various production sectors - supported 4.3 million jobs in 1996, a decline of 80,000 over the decade. Non-basic/basic ratios are meaningless. New jobs are overwhelmingly service jobs.

Table 1: Growth rates by service sector: Canada, 1986-1996

\begin{tabular}{|c|c|c|c|c|c|c|c|}
\hline & \multicolumn{2}{|c|}{1986} & \multicolumn{2}{|c|}{1996} & \multirow{2}{*}{$\begin{array}{r}\text { 1986-1996 } \\
\text { Jobs }\end{array}$} & \multirow{2}{*}{$\begin{array}{r}\text { Change } \\
\text { Share }\end{array}$} & \multirow{2}{*}{$\begin{array}{r}\text { Per Cent } \\
\text { Change }\end{array}$} \\
\hline & Jobs & Share & Jobs & Share & & & \\
\hline Wholesale & 540.0 & $11.7 \%$ & 667.1 & $11.4 \%$ & 127.2 & $10.4 \%$ & $23.6 \%$ \\
\hline RETAIL & 1466.1 & 31.7 & 1655.9 & 28.3 & 189.8 & 15.5 & 12.9 \\
\hline Convenience $^{\mathrm{a}}$ & 740.0 & 16.0 & 888.4 & 5.2 & 148.4 & 12.1 & 20.0 \\
\hline Shopping & 726.1 & 15.7 & 767.5 & 13.1 & 41.4 & 3.8 & 5.7 \\
\hline Finance & 653.1 & 14.1 & 756.3 & 12.9 & 103.3 & 8.4 & 15.8 \\
\hline Commercial Service & 1964.1 & 42.5 & 2767.0 & 47.3 & 802.9 & 65.6 & 40.9 \\
\hline Business & 540.8 & 11.7 & 881.5 & 15.1 & 340.7 & 27.9 & 63.0 \\
\hline Recreation $^{\mathrm{b}}$ & 835.7 & 18.1 & 1125.5 & 19.3 & 289.8 & 23.7 & 34.7 \\
\hline Personal $^{\mathrm{c}}$ & 587.6 & 12.7 & 760.0 & 13.0 & 172.4 & 14.1 & 29.3 \\
\hline Total Commercial & 4623.2 & 100.0 & 5846.3 & 100.0 & 1223.2 & 100.0 & 26.5 \\
\hline Government $^{\mathrm{d}}$ & 2668.1 & na & 3149.0 & na & 480.9 & na & 18.0 \\
\hline Other Sectors & 4377.2 & na & 4315.6 & na & -81.7 & na & -1.9 \\
\hline Total Employment & 11668.5 & na & 13310.9 & na & 1622.4 & na & 13.9 \\
\hline
\end{tabular}

${ }^{a}$ food, automotive, ${ }^{b}$ accommodation, food and recreation ${ }^{c}$ personal membership, miscellaneous

${ }^{d}$ public service, education, health

Number of Jobs in 1000s. 
Services need markets, and they respond to market growth, so many of the new jobs are created where the production jobs and population already exist. In that sense service activities are spatially conservative. But occasionally, some major developments in tourism, or health care facilities, or government jobs may alter the urban system - such as a decision to downsize public administration. For the most part, though, the impacts of the growth in services are subtle, such as a modest shift in favour of larger cities or richer cities, or cities with better accessibility.

This paper describes an old-fashioned economic base analysis focussed on services. It was prepared for the latest edition of the Atlas of Canada, as a way of mapping the distribution of service activity. We began with service employment for about twenty categories for about 160 urban places with more than 10,000 population. In order to control for the size of the local market we applied a logarithmic regression to explain service employment in terms of the city's population and income per capita (Table 2). The results of the equation for all commercial employment indicate that these services are still closely linked to the local market, since the regression model explains over 98 per cent of the variance. The fact that the population coefficient is greater than one indicates that commercial employment increases disproportionately with city size. A city that is ten time larger will have eleven times as much employment. In contrast, the regression coefficient for income per capita is only 0.5 , which suggests that an increase in income per capita is only partially captured as local consumption. The money may be invested elsewhere, or spent in larger cities, or used for travel. The biggest cities tend to have the highest incomes, and this weakens the effecttiveness of the income measure.

Table 2:The regression models

$\log _{10}$ (Service Employment)

$=\mathrm{A}+\mathrm{B}_{1}\left(\log _{10}(\right.$ Population $\left.)\right)+\mathrm{B}_{2}\left(\log _{10}(\right.$ Income/Capita $)$

$\mathrm{R}^{2}=$ Coefficient of Determination

For All Commercial (Private Sector) Services:

$=-3.086+1.039 \log$ Population $+0.507 \log ($ Income/Capita $)$

$\mathrm{R}^{2}=0.989$

The regression measures the 'hierarchical' variation in service activity: how it relates to market size. The parallel concern is the 'horizontal' variation among cities, measured as the residuals from the regression. We call this variation 'Centrality" since it identifies Ca-ada's central places, the cities that serve extended trade areas outside their boundaries. Think of it as the location advantage enjoyed by a city that serves other nearby cities or surrounding rural areas. The result of the advantage is a service sector that has more stores, sales and jobs than would be normally expected from the size of the market. The index can be interpreted as the ratio of the city's service employment to the employment norm de-fined by all cities. Nationally, the map contrasts the central places of western Canada that serve exten- 
sive agricultural regions, with the manufacturing and mining cities of Central Canada that may purchase services from nearby cities. But within Central Canada smaller cities that are close to Toronto or Montreal may have higher indices of centrality. The smallest values occur in isolated mining towns in the north. Note that, in this type of regres-sion, the largest cities tend to have the smallest residuals, and have fewer extreme values. Clearly, centrality can be a considerable advantage for smaller cities, with service employ-ment levels ranging as much as 35 per cent above and below the values predicted by the size of the market. And centrality begets further growth as new services seek out urban places that are able to attract customers.

Figure 1: The centrality index

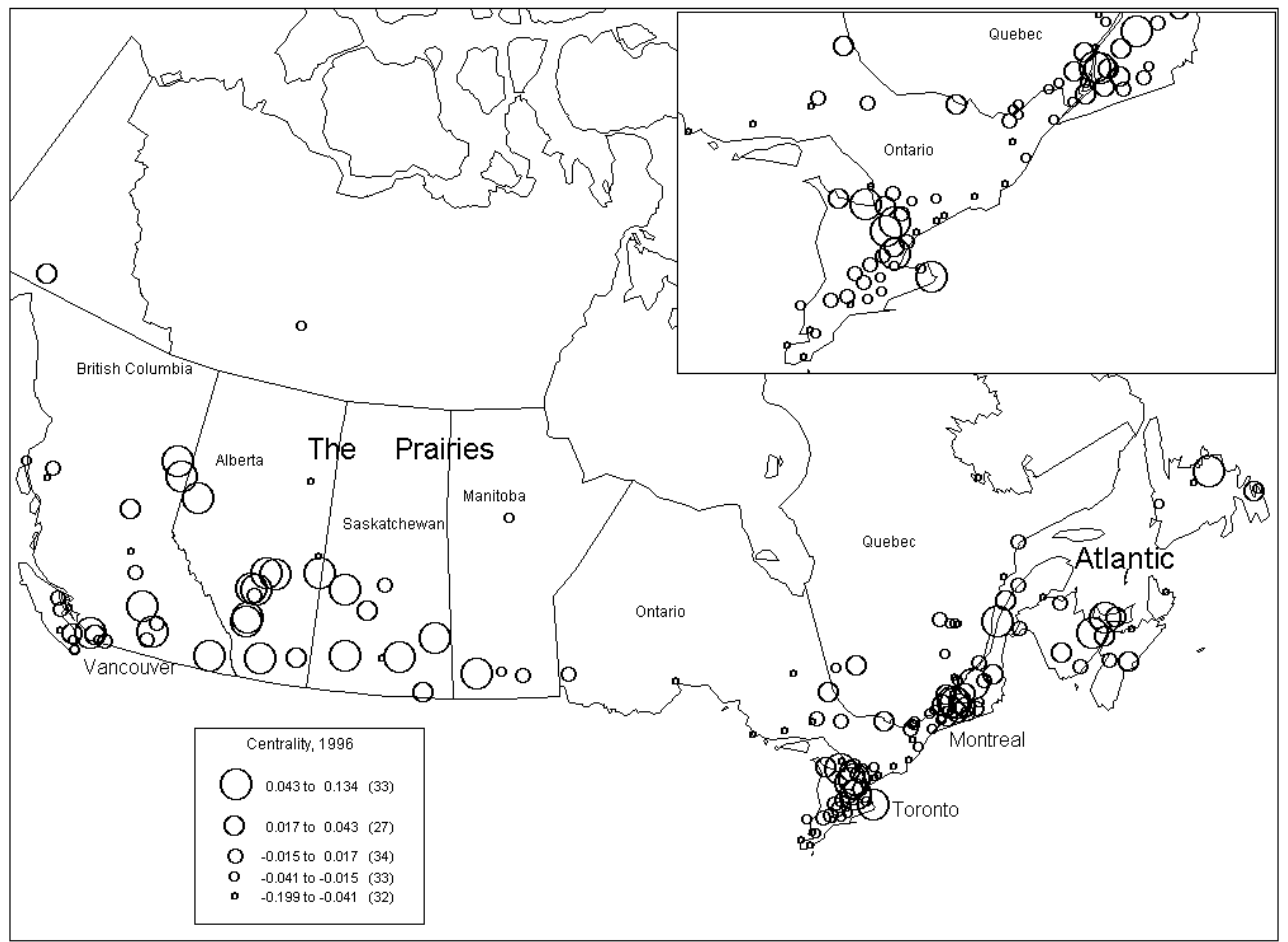

\section{SPECIALISATION IN SERVICES}

The equation presented above, and the map of centrality, define the overall specialization in commercial services. This pattern is very powerful and underlies many of the distributions for specific services. At the same time, however, it is possible to identify both the hierarchical and horizontal variations in the geography of particular services by generating a separate equation in each specialization. The equations are described in Table 3 , and maps of each specialization are available on the Internet (see the references). The coefficient of 
determination $\left(\mathrm{R}^{2}\right)$ indicates how regular or predictable the various service distributions are. The lowest values identify the sectors that are most spatially removed from their consumers, such as wholesaling, business services and finance. $\mathrm{B}_{1}$, the population regression coefficient, indicates the propensity to locate in larger cities. The values are greater than one for all services except retail convenience (food and automotive) and recreation (tourist services). The activities with the highest values (most closely associated with big cities) are business services, finance, and wholesale. The relationship with income, $\mathrm{B}_{2}$, shows the greatest variation in value, ranging from minus 0.225 to plus 1.470 , indicating how consumers divert their spending as their incomes increase. Convenience retail is strongest in low income markets, but as incomes increase, business services, finance, and recreation absorb more consumer spending. It is clear that many service activities are extremely income sensitive - even within the relatively restricted income range that exists among cities (restricted compared to the income differences among urban neighbourhoods). Note that public sector employment is relatively insensitive to income levels. The maximum and minimum values show the range of values around the predicted levels of employment.

Table 3: Evaluating specialization: The regression results

\begin{tabular}{|l|r|r|r|r|r|r|}
\hline & \multicolumn{1}{|c|}{$\mathrm{R}^{2}$} & \multicolumn{1}{|c|}{ Intercept } & $\begin{array}{c}\text { Population } \\
\text { Coefficient }\end{array}$ & $\begin{array}{c}\text { Income } \\
\text { Coefficient }\end{array}$ & $\begin{array}{l}\text { Maximum } \\
\text { Variations }\end{array}$ & $\begin{array}{c}\text { Minimum } \\
\text { Variations }\end{array}$ \\
\hline Commercial $^{*}$ & 0.989 & -3.060 & 1.039 & 0.507 & $36.0 \%$ & $-36.7 \%$ \\
\hline & 0.987 & -0.986 & 1.055 & & 43.2 & -34.8 \\
\hline Wholesale & 0.926 & -4.620 & 1.089 & 0.583 & 136.2 & -73.6 \\
\hline Retail & 0.987 & -0.734 & 0.987 & -0.096 & 55.4 & -31.5 \\
\hline Convenience & 0.985 & -0.252 & 0.946 & -0.225 & 52.4 & -33.9 \\
\hline Shopping & 0.976 & -2.017 & 1.039 & 0.064 & 62.4 & -44.6 \\
\hline Finance & 0.967 & -5.275 & 1.115 & 0.712 & 106.0 & -55.6 \\
\hline Service & 0.986 & -4.853 & 1.051 & 0.836 & 56.1 & -34.9 \\
\hline Business & 0.953 & -8.795 & 1.179 & 1.470 & 138.8 & -73.1 \\
\hline Recreation & 0.972 & -3.824 & 0.998 & 0.572 & 86.5 & -43.1 \\
\hline Personal & 0.985 & -3.911 & 1.035 & 0.506 & 65.0 & -38.3 \\
\hline Government & 0.969 & -1.778 & 1.033 & 0.158 & 27.9 & -20.7 \\
\hline
\end{tabular}

* Commercial does not include government

Wholesale identifies a distinctive economic specialization, including several sub-centres close to metropolitan regions. The cities that lack wholesale, however, include the same set of peripheral locations as the services in general. The retail specialization largely repeats the aggregate pattern. Finance and business services are the most urban-oriented services, although these activities may now be dispersing into high-income suburbs near the larger cities. Recreation shows a quite different pattern, with several smaller communities doing well, while the places that were strong in business services lag behind. As one might expect, government employment (including education and health services) tends to be concentrated in national and provincial capitals, and places that have attracted special public 
sector facilities. At the same time, the places with negative residuals for the public sector have similar low values for commercial activity. Centrality counts just as much in the public sector as in the private. As a generalization, it appears that while there are many different potential locations for specialization in services, the locations of service deficiency are similar for all activities.

Service specialization is a multi-dimensional concept. Some places sell cars, while others specialize in recreation or business services. Those places that specialize in the services that grow are going to grow as well.

\section{THE GROWTH OF SERVICES}

Table 1 looked at the amount and pattern of change in service employment across the Canadian urban system between 1986 and 1996. In aggregate, the level of commercial service activity in urban areas increased by 25.8 per cent, compared to only 5.8 per cent for other economic activities. This growth rate compares to 16.3 per cent growth for population and 22.7 per cent for the market (the total income). The numbers suggest that commercial services and service locations are absorbing employment growth from other sectors and other locations, and thus driving the national growth pattern. Commercial services have contributed three-quarters of the jobs created during this time period. Almost every city added service jobs. Is this a universal process of shifts among economic sectors that occurs in all locations; or is it restricted to those locations that attract services?

The consistency in the rates of service growth in all types of locations supports the idea of universality (Table 4). Relatively little difference in growth rates is observed among the various urban size classes, although the smaller cities have grown slightly faster. Even the regional variations are minimal, with the exception of the extraordinary growth that took place in British Columbia during this period - a rate of growth that has since declined considerably. The Table also includes information about the variability of growth rates among the different groups of cities, as the Coefficient of Variation (standard deviation/ mean). In this case marked differences exist between the various urban size groups. The larger, more diverse, cities tend to grow at the national rate; while smaller, more specialized, places are less predictable.

The map (Figure 2) shows that growth is concentrated regionally, in British Columbia and Alberta and around the largest metropolitan centres in Central and Eastern Canada, showing a close relationship with market growth. Growth is slow in the agricultural centres of Mani-toba and Saskatchewan and in smaller places in Central Canada. In general the growth pattern diverges from the centrality index in the Prairies, but reinforces it in the East. Table 5 explores the relationships among changes in the variables that concern us. First, consider the triangle of correlation coefficients in the upper part of the table. These describe the commercial system in cross-section in 1986. The market is the product of population and income per capita, with the former playing the larger role - hence the higher level of corre-lation. The distribution of service employment is largely explained by the market, although centrality, as explained above, also makes a small contribution. 
Table 4: Employment growth rates, by city size and region, 1986-1996 (Commercial Service Sectors)

\begin{tabular}{|l|r|r|r|r|r|r|r|}
\hline Urban & BC & Prairies & Ontario & Quebec & Atlantic & Total & C.of V.* \\
\hline One Mil- & $40.7 \%$ & $\ldots$ & 22.9 & 20.4 & $\ldots$ & 25.4 & 0.397 \\
\hline $300,000+$ & 36.9 & 23.7 & 22.5 & 26.2 & $\ldots$ & 23.4 & 0.393 \\
\hline $100,000+$ & 37.9 & 11.5 & 24.5 & 30.1 & 18.2 & 22.8 & 0.523 \\
\hline $30,000+$ & 61.4 & 19.1 & 26.2 & 26.6 & 24.7 & 32.7 & 0.755 \\
\hline $10,000+$ & 41.1 & 22.6 & 27.9 & 33.9 & 18.8 & 29.2 & 0.840 \\
\hline Total & 44.8 & 21.5 & 23.5 & 23.5 & 19.4 & 25.8 & 0.780 \\
\hline C. of V. ${ }^{*}$ & 0.411 & 1.023 & 0.865 & 0.746 & 1.636 & $\ldots$ & 0.780 \\
\hline
\end{tabular}

* Coefficient of Variation = standard deviation/mean of the growth rates of the cities within the category.

Figure 2: Growth of commercial employment, 1986-1996

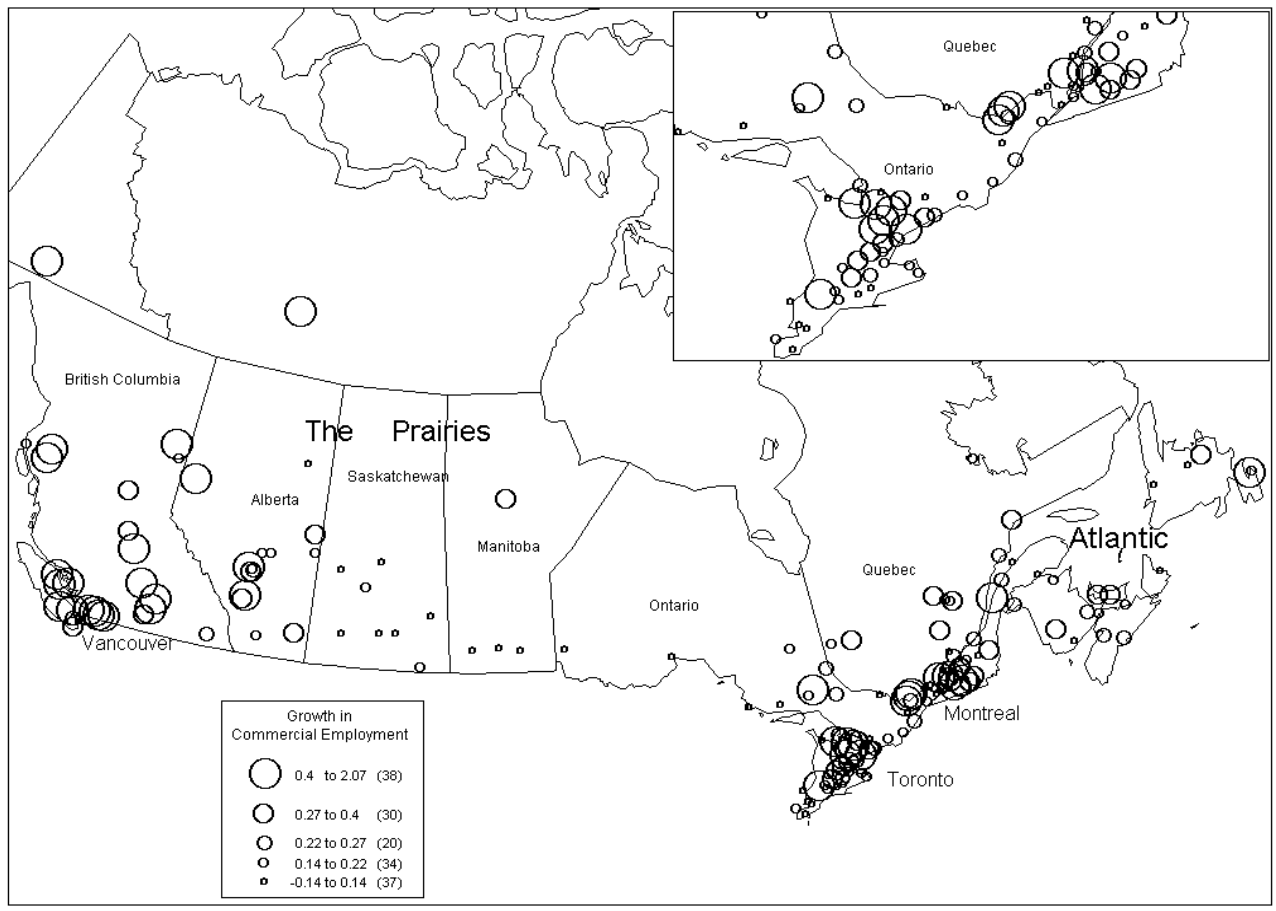

The triangle of relationships on the right-hand side of the table explores the interaction among the changes in these variables. Again, the growth of the market reflects the growth of population and income per capita. And the growth of services is linked to the growth of the market, as well as the increase in centralization. The change in centralization is simply calculated as the difference between the centralization measures in 1996 and 1986; it is logically linked to the growth in service employment, but there is no relationship with the growth in the market. A regression model for the employment growth rates explained $54 \%$ 
of the variance, using the growth in population and the growth in income per cap-ita. Part of the residual variation may be due to the shifts in the patterns of centrality or specialization among cities. Peripheral locations in British Columbia improved their posi-tions, while similar locations in Ontario fell behind.

Table 5: Growth relationships, 1986-1996 (correlation coefficients)

\begin{tabular}{|l|c|c|c|c|c|c|c|c|c|c|}
\hline Variables & \multicolumn{1}{c|}{1.} & \multicolumn{1}{c|}{2.} & \multicolumn{1}{c|}{3.} & \multicolumn{1}{c|}{4.} & 5. & 6. & 7. & 8. & 9. & 10. \\
\hline \hline 1. Comm. Emp. & 1.00 & & & & & & & & & \\
\hline 2. Population & .989 & 1.00 & & & & & & & & \\
\hline 3. Income/Capita & .406 & .350 & 1.00 & & & & & & & \\
\hline 4. Market & .990 & .995 & .442 & 1.00 & & & & & & \\
\hline 5. Centrality & .086 & -.038 & -.002 & -.035 & 1.00 & & & & & \\
\hline \hline 6. Growth in (1) & -.098 & -.108 & .122 & -.099 & -.048 & 1.00 & & & & \\
\hline 7. Growth in (2) & .056 & .030 & .258 & .056 & .238 & .861 & 1.00 & & & \\
\hline 8. Growth in (3) & -.248 & -.231 & -.263 & -.250 & -.159 & .314 & .111 & 1.00 & & \\
\hline 9. Growth in (4) & -.018 & -.053 & .148 & -.035 & .164 & .885 & .946 & .424 & 1.00 & \\
\hline 10. Change in (5) & -.079 & -.028 & .085 & -.018 & -.456 & .426 & -.028 & .049 & -.009 & 1.00 \\
\hline
\end{tabular}

In order to explore the direction of change consider the remaining rectangle of correlations that link the cross-sectional characteristics of the urban system in 1986 to the rates of change. Most of the correlations are very small. This suggests that the growth of markets and commercial activity is largely unrelated to the a priori characteristics of cities such as the population or income per capita. In short, it is difficult to project future growth based on current conditions. Population growth correlates slightly with income and centrality in 1986, but this is offset by the negative relationship between income growth and the size of the market. The most interesting patterns involve the changes in centrality. While the growth in population and the market are positively correlated (weakly) with centrality in 1986, the growth in commercial employment and the growth in income show a slightly negative correlation with centrality. Note the strong negative correlation $(-0.456)$ between the level of centrality in 1986 and the change over the decade. Commercial activity has apparently dispersed into places that previously had low values for centrality. Of course, centrality is simply the residual from a regression and residuals tend to revert to the mean values. The correlation between centrality measures for the two time periods was 0.758 .

\section{CONCLUSIONS}

1. Over the last twenty years the service sectors have taken over the direction of the Canadian space economy. It is not that the production sectors are less important within the economy, but that they no longer determine the location of growth by creating jobs. Sometimes the jobs are diverted away from production, in headquarters cities or in business services; sometimes the resource revenues they generate lead to jobs for 
nurses or teachers within the province; and sometimes the closing of a mine or factory spells the end of a small community; but for the most part the changes in production jobs are overwhelmed by the growth of service jobs.

2. Often these changes go unnoticed because the expansion of services tracks the location and growth of existing markets. Production jobs are converted to service jobs nearby. Higher incomes are spent on services. We tend to ignore the importance of the regional hospital or the new shopping centre along the highway on the edge of town, although they create hundreds or even thousands of jobs.

3. Gradually these economic shifts are having an impact on the differential growth of cities, especially as the overall growth rate of Canadian cities declines. (In the recent Census of Canada, more than half the cities with population less than 250,000 lost population!). For example, much of the growth of large cities is driven by the expansion of business and financial services. Provinces are carrying out a kind of triage, as they allocate health care facilities among small cities that are thriving or dying, or in critical condition. Resort and retirement centres are attracted to amenities, rather than production sites.

4. Our studies suggest that future urban growth will be based on the location of services, with the key elements:

a) the hierarchical attractions of market size, as business and financial services concentrate in larger centres.

b) the horizontal factor of access to regional markets (centrality), with private and public sector services relocating from primary production sites toward regional central places.

c) amenities for recreation and retirement attracting consumer services to selected smaller centres.

d) centres for public administration (but not health or education services) losing ground to commercial centres.

\section{References}

Simmons, J., Jones, K., and Bylov G. 2002. "The Status of Retail and Commercial Activity in Smaller Centres." Research Report 2002-06. Toronto: Centre for the Study of Commercial Activity, Ryerson University.

http://atlas-dev.ccrs.nrcan.gc.ca/site/english/maps_a_to_z/index_html 